On October 4 the round-table concept was continued with a discussion on exploration of the solar system by radar and radio astronomy, the Moon and Venus being considered in the morning and Jupiter and future experiments in the afternoon. The radio reflexion experiments from the surface of the Moon appear to show fairly conclusively that much of the Moon is covered with a layer of dust having a thickness less than $1 \mathrm{~cm}$. The session on Jupiter was of interest on account of the detailed deseription of the radio emissions from the Great Red Spot. The nature of these emissions is now fairly well established, but their cause appears to remain a mystery.

The most significant communication at the Conference was given by the Russian delegation, who revealed that their cosmonaut Titov was space-sick throughout the duration of his 24-hr. trip around the Earth, although this did not prevent him from sleep. ing in accordance with plans, or from carrying out routine duties which had been assigned to him.

On October 5 the weather was fortunately much better, and the now traditional conforence boat-trip was made down the River Potomac past the Naval Research Laboratory's radio telescope, on to Mount Vernon. This informal occasion probably gives more opportunity for relaxed discussion between ad hoc groups of experts than is possible in the more formal atmosphere of the conference hall. The Congress banquet was held in the evening and was addressed by Academician Sedov.
On October 6 another British paper was presented, "Blue Streak as First Stage of a Satellite Launcher", by G. K. C. Pardoe. This described the present position of Britain's only large rocket, based on the design of the American Atlas rocket, which is the largest they have attempted to fire to date. No particular reference was made to possible British or European payloads, although possible European collaboration in the future was mentioned. Simul. taneously, there was a round-table meeting on space communications, but most amazingly no reference was mado to the use of radio, which is of course the obvious way for exploiting space for communications purposes. The signals to be conveyed would be modulated on to bcams of light emitted from optical mosers. This method gives a promise of tremendous band-width at some remote time in the future. Use of ultraviolet light for communications was proposed by Mr. J. W. Ogland, and one rather speculative paper suggested the use of $\gamma$-rays for communications. If the vehicle is propelled by a nuclear rocket, the $\gamma$-rays are available as a by-product and some form of hinged lead sheet has to be contrived for signalling purposes. This method is limited to use in space in the absence of any atmosphere and was shown to work at ranges up to 100,000 miles, but the signalling frequency is limited to one cycle per second.

Finally, on Octoker 7, delegates were taken on a tour of the NASA Goddard Space Flight Center at Goddard, Maryland.
W. F. HiLton

\title{
THE VEHICLE DRIVER
}

A MEETING of the British Occupational Hygiene Society was held at the Traffic and Safety Division of the Road Research Laboratory during November 9-10. Six papers were read and discussed; for the first two, which dealt with bus drivers, the chair was taken by Dr. L. G. Norman, the president of the Society.

Examination by Dr. P. Froggatt of data from Northern Ireland revealed that a curve of accidentrate plotted against age of driver had a broad minimum over the ages $45-55$ years which was due to the beneficial results of experience being opposed by the decline in performance with advancing age. The accident-rate of experienced drivers rose above 50 vears of age.

Mr. C. J. Cornwall had examined the records of London bus drivers for the poriod 1957-59 for which the average rate was 1.37 accidents per driveryear on a mileage of about 14,000. Accidents were associated with traffic density. The accident-rate fell with increasing experionce more rapidly than it rose with age; the fall was marked up to 47 years and slower up to 70 . Replacements of old drivers by younger men would increase the number of accidents.

Dr. R. J. Smeed, deputy director of the Road Rosoarch Laboratory, occupied the chair during a session which was opened by Mr. W. Gissane, who described the nature and cause of injuries resulting from motor-car accidents in a city. SquadronLeader D. I. Fryer told of the development of safety belts in aircraft, going back to Colonel Cody, who was the first man to fly a powered machine in England. The design and testing of modern safety-belts were described in detail, and the value of rearwardsfacing seats, adequately attached to the airframe, was emphrsized.
Road experience with safety belts was dealt with by Dr. A. J. Moreland, who approached the problem of assessing accidents quantitatively by defining a damage index. This number was evaluated from the damage to chassis, compartment and bodywork. When divided by the weight of the motor-ear it correlated well with the difference between the squares of the velocities of the objects coming into contact.

The damage index divided by weight was used as a basis for comparing the frequency of casualties of various degrees. Fatalities commenced at a figure near 15 and rose steadily; serious injuries rose from near the origin while slight injuries attained a maximum at about 25.

Safety belts of good design, firmly attached, could prove beneficial, but there were suggestions that people drove faster when wearing them, and they did not check the forward velocity of the head on impact or protect it from objects flung forward from the rear. The steering arrangements, likewise, might either promote injury or provide protection.

The final paper was delivered by $\mathrm{Mr}$. I. D. Brown with Prof. D. D. Reid in the chair. Observations of police and other skilled drivers had been used in an attempt to relate driving performance to fatigue and distraction. It seemed likely that there was spare capacity to draw on in case of need and that fatigue from general occupations before driving might be more serious than that induced by driving. Tests of distraction by using tape recordings in which the subject was either interested, or not interested, were also carried out.

The Road Research Laboratory demonstrated the telemetering of movements of the controls of a vehicle under way, of recording what happens in an accident and of experimental collisions. The incorrect basis of 
early tests on motor-cycle crash-helmets was shown and specimens illustrated the protection afforded by helmets and the distribution of the injuries of motorcyclists.

The bulk of the meeting was concerned with the results of accidents and diminution of their effects on people; little attention was given to the prevention of motor-car accidents by methods within the control of the vehicle driver. The papers and discussion will be published in the Annals of Occupational Hygiene.

\section{N. Davies}

\section{MECHANISMS OF VIRUS INFECTIONS}

A DISCUSSION meeting of the Royal Society, arranged by Prof. Wilson Smith, on the subject of "Mechanisms of Virus Infections", was held on November 2. Owing to the large numbers attending, the meeting was transferred, by courtesy of Sir Lawrence Bragg, to the lecture hall of the Royal Institution. The president of the Royal Society, Sir Howard Florey, took the chair.

In his introduction, Prof. Wilson Smith traced briefly the progress of virological knowledge from the early almost metaphysical questioning into the nature of viruses to the present wealth of information regarding their chemical constitution, structure and intracellular behaviour. He wondered, however, whether these particular aspects were not in danger of being over-emphasized at the expense of more traditional problems relating to virus disease. The natural history of any virus disease is intimately related to the survival cycle of the virus concerned and, in the metazoon host, this cycle is necessarily complex. The route of infection and primary lodge. ment, paths and mechanisms of spread through the host, replication and ultimate release must be considered at the various levels of the eell, the intact host and the host population. It was with this in mind that the present programme had been built up around the concept of the survival cycle.

Prof. A. W. Downie (University of Liverpool) opened the discussion with a paper on "Mechanisms of Virus Entry and Spread within the Host (Animal Viruses)". Although a rapid survey of the various routes of infection known to occur was given to illustrate the extent of the subject, and problems associated with the question of neurel spread in such diseases as poliomyelitis, herpes and pseudo-rabies were briefly discussed, the paper was centred on the pathogenesis of disease in the pox group of viruses. Fenner's detailed work on ectromelia has laid a pattern which serves as a standard of reference for investigations with other members of this group, and a study of the highly lethal rabbit pox infection shows that it follows the same general course. The main difference is that the stages of primary and secondary lodgement with final involvement of the skin, and of primary and secondary viræmia, are less well defined in rabbit pox than in mouse pox. Despite thorough investigation of animals infected by the intra-nasal route, no primary lesion is identifiable although virus can be readily demonstrated in the tissues of the nasal passages and trachea. The blood contains virus as early as the second day after infection and thereafter remains positive. Clinical disease develops on the fourth day. The finding that provoked the greatest interest and discussion was that animals do not become infectious by contact until the fifth or sixth day, at least $24 \mathrm{hr}$. after the onset of clinical disease, a finding elosely similar to that in human smallpox. Following intranasal infection, virus may be isolated from the tissues of the upper respiratory tract in rabbit pox, and smallpox virus is presumed to invade by this route in the majority of human cases. Why then is the patient not infective during the incubation period ? Dr. C. H. Cadman (Scottish Horticultural Research Institute) dealt with the same subject in its relation to plant viruses and pointed out that there is an essential difference in the problems involved, since plant viruses are unable to effect entry into the tissues without external aid. Trauma is an essential prerequisite to infection and is usually inflicted in Nature by insect vectors. In the laboratory the necessary damage is achieved by rubbing the leaf, but the inefficiency of this procedure may be gauged from the fact that about $10^{6}$ infective particles are necessary in order to produce a lesion. Further, since the plant does not possess conveniently isolated internal organs which can be segregated by dissection and to which the virus can track, spread of virus cannot be followed as in the animal host. It is probable that virus spreads in the translocation stream, but if so the form of the virus at this time is not known. Since certain viruses are apparently capable of dispensing permanently with their protein coat, it is possible that spread within the plant occurs in the form of ribonucleic acid. The possible role of plasmodesmata and the problem presented by the fact that virus appears to spread through callus tissue cultures just as fast as through intact plant tissues were also discussed.

It was clear from both these papers, in their different contexts, that there is a long way to go before the problems of virus invasion of host tissues can be considered to be satisfactorily explained.

"Intracellular Replication Mechanisms" were discussed by Prof. M. Stoker (University of Glasgow), who considered the subject from the point of view of the interrelationship of virus growth to cell growth. The types of interrelationship exemplified by bacteriophage infection are: (1) the extreme virulence found in the $T$-even phage where adsorption of the protein coat is sufficient to cause immediate death of the cell with breakdown of deoxyribonucleic acid; (2) intermediate virulence where the host cell is not immediately killed but cell division is prevented; and (3) the avirulent prophage relationship. In the case of animal viruses, infection usually results in death of the cell, and the difficulties in demonstrating noncytopathic infection of cells were discussed in detail. For proof it is necessary to study isolates of single cells and demonstrate, first, release of virus and, second, cell division in that order.

Prof. Stoker concluded that there is as yet no satisfactory evidence for infections of this type with normally cytopathogenic viruses, but this has recently been acquired by Rubens with the Rous sarcoma virus so that this virus, which is not normally cytopathogenic, is the only one for which the formal criteria have been satisfied. In the case of polyoma virus, either cytopathic effect or cell transformation may follow infection in vitro; but in the latter case, it has not proved possible to demonstrate virus in the 